\title{
Cell Membrane Reactivity of MIB-1 Antibody to Ki67 in Human Tumors: Fact or Artifact?
}

\author{
Eugenio Leonardo, MD, * Marco Volante, MD, $\dagger$ Mattia Barbareschi, MD, $\ddagger$ \\ Alberto Cavazza, MD,§ Angelo Paolo Dei Tos, MD,\| Gianni Bussolati, MD FRCPath, $\emptyset$ \\ and Mauro Papotti, MD†
}

\begin{abstract}
Ki67 immunohistochemistry is a widely used marker of the tumor proliferative fraction. Apart from the nuclear staining of dividing cells, MIB-1 monoclonal antibody was also found to stain the cell membrane of some tumor types. Indeed, such membrane reactivity was proposed as a diagnostic feature of hyalinizing trabecular tumor (HTT) of the thyroid. To verify the diagnostic role of Ki67 membrane pattern, 6 HTTs, 8 pulmonary sclerosing hemangiomas $(\mathrm{SH})$, and 6 other human tumors with MIB-1 cell membrane immunoreactivity were stained by immunoperoxidase with 5 different anti-Ki67 antibodies in different experimental conditions. We show here that the cell membrane reactivity reported in HTT is produced only by MIB-1 and not by other antibodies to Ki67 (including commercially available mouse and rabbit monoclonal antibodies). In addition, this peculiar pattern is obtained only if the reaction is performed at room temperature, because automated immunostainers which operate at $37^{\circ} \mathrm{C}$ do not produce any MIB-1 membrane localization. The same findings were obtained in the other 6 tumors. Conversely, sclerosing hemangioma of the lung did not produce any MIB-1 cell membrane reactivity in our hands. A cross-reactivity of the MIB-1 monoclonal antibody with an epitope expressed at the cell membrane level (rather than an artifact) seems the most likely explanation for this finding, because the immunoreactivity is generally intense and uniform in the membrane positive tumors. We conclude that when Ki67 immunohistochemistry is used for diagnostic purposes in a suspected HTT, only MIB-1 clone at room temperature should be employed.
\end{abstract}

Key Words: Ki67, MIB-1, immunohistochemistry, membrane, carcinoma, thyroid, hyalinizing trabecular tumor

(Appl Immunohistochem Mol Morphol 2007;15:220-223)

Received for publication March 15, 2006; accepted April 27, 2006.

From the *Division of Pathology, San Luigi Hospital, Orbassano; $\dagger$ Department of Clinical and Biological Sciences, University of Turin and San Luigi Hospital; \$Unit of Anatomic Pathology, S. Chiara Hospital, Trento; §Department of Histopathology, Arcispedale S. Maria Nuova, Reggio Emilia; \|Division of Pathology, Civil Hospital, Treviso; and Department of Biomedical Sciences and Oncology, University of Turin, Italy.

Supported by grants from the Italian Ministry of University and Research (ex-60\% to MP).

Reprints: Mauro Papotti, MD, Department of Clinical and Biological Sciences, University of Turin and San Luigi Hospital, Regione Gonzole 10, 10043 Orbassano, Torino, Italy (e-mail: mauro.papotti@ unito.it).

Copyright (C) 2007 by Lippincott Williams \& Wilkins $\mathrm{t}$ is well known that the nuclear Ki67 antigen is expressed during all cell cycle phases, but $\mathrm{G}_{0}{ }^{1}{ }^{1} \mathrm{Ki} 67$ immunostaining is therefore the most common histopathologic method to assess the tumor cell proliferation index $(\mathrm{PI})$, in routine formalin-fixed paraffin-embedded samples. ${ }^{2}$ In the literature, several studies have been reported on the prognostic role of the PI in neoplastic patients. The survival rate correlates with the percentage of Ki67 positive neoplastic cell of larynx, urogenital, digestive, and endocrine carcinomas. ${ }^{3,4}$ In other neoplastic lesions (eg, neuroendocrine tumors), the PI is one of the parameters leading the therapeutic strategy. ${ }^{5}$

Ki67 immunostaining has also been proposed for diagnostic purposes, such as to differentiate benign (low PI) from malignant epithelial and mesenchymal lesions (high PI), to discriminate between typical and atypical bronchial carcinoids ${ }^{6,7}$ and to take benign apart from malignant parathyroid and adrenocortical tumors. ${ }^{8}$ Another useful immunohistochemical application of Ki67 is the localization and distribution of proliferating nuclei in pluristratified and pseudostratified epithelial lesions to grade the cervico-uterine and bladder urothelial lesions. $^{3,9,10}$ Ki67 is also useful in the differential diagnosis of follicular lymph node lesions, that is, follicular hyperplasia versus follicular lymphoma. ${ }^{11}$

The proliferative activity, as detected by Ki67 expression, is usually evaluated by means of the monoclonal antibody MIB-1, which recognizes a Ki67 epitope in archival, paraffin-embedded material. Recently, a peculiar cell membrane stain of Ki67 has been described in hyalinizing trabecular tumor (HTT) of the thyroid, suggesting that such membrane pattern was diagnostic in these lesions. ${ }^{12-15}$ In sclerosing hemangioma $(\mathrm{SH})$ of the lung (but not in a control group of conventional pulmonary carcinomas), a similar pattern was described in association with cytoplasmic staining. ${ }^{16}$

Recently, we happened to use Ki67 immunostaining to confirm the diagnosis of a case of HTT of the thyroid, but we had negative results. Therefore, an analysis of several commercially available anti-Ki67 antibodies in different technical conditions was designed with the aim of verifying if the cell membrane staining reported in HTT and, occasionally, in other human tumors was related to a specific Ki67 antibody clone and/or specific experimental conditions. 


\section{MATERIALS AND METHODS}

A case of sarcomatous pleural mesothelioma with focal Ki67 cell membrane reactivity and 6 cases of HTT of the thyroid were retrieved from the pathology files of the University of Turin at San Giovanni Hospital. The clinicopathological and molecular data of HTT cases were reported elsewhere. ${ }^{13,17}$ In addition, 4 cases of invasive breast carcinoma having a membrane reactivity were collected from the pathology files of the Treviso ( 3 cases) and Trento (1 case) Hospitals; 2 of them had been included in a study on rabbit monoclonal antibody applications in diagnostic immunohistochemistry. ${ }^{18}$ Finally, 8 cases of $\mathrm{SH}$ of the lung and 1 case of renal oncocytoma were retrieved from the pathology files of the Arcispedale S. Maria Nuova, Reggio Emilia (3 SH), Ospedale S. Chiara, Trento (1 SH), and San Luigi Hospital in Orbassano, Turin (4 SH and 1 renal oncocytoma).

A representative formalin-fixed, paraffin-embedded tissue block was selected for each case and 5- $\mu \mathrm{m}$-thick serial sections were dewaxed, rehydrated, and processed for immunoperoxidase using different Ki67 antibody clones and different technical conditions, as summarized in Table 1. For all Ki67 antibody clones tested, antigen retrieval was based on three 5-minute passages in microwave oven at $750 \mathrm{~W}$ in $10 \mathrm{mM}$ citrate buffer solution at $\mathrm{pH}$ 6. Streptavidin-biotin-peroxidase complex (LSAB DakoCytomation, Glostrup, Denmark) and biotin-free methods (EnVision, DakoCytomation) were used to detect the immune reaction. Diaminobenzidine and hydrogen peroxide were applied as chromogen and substrate, respectively. Both manual and automated immunostains (DakoCytomation and Ventana, Tucson, Arizona) were performed for each antibody, at room temperature or at $37^{\circ} \mathrm{C}$, respectively.

\section{RESULTS}

Automated immunostains and manual methods showed basically the same pattern at comparable experimental conditions. No differences were observed using the 2 different detection systems (either biotin-based or biotin-free). In all selected lesions, except for SH cases, tumor cells showed membrane and (occasionally) cytoplasmic staining only when MIB-1 clone (either from DakoCytomation or from Immunotech) was used at room temperature (Fig. 1). No MIB-1 membrane reactivity was found when immunostaining was performed at $37^{\circ} \mathrm{C}$ with the same clone. No Ki67 membrane localization was observed when any other clone (from both mouse and rabbit sources; Table 1) was employed, irrespective of the incubation temperature of the antibody. In these same cases, MIB-1 nuclear staining was detected in proliferating tumor cells, as expected, and in few reactive lymphocyte nuclei, irrespective of the reaction temperature.

\section{DISCUSSION}

$\mathrm{Ki} 67$ is a nuclear protein expressed during the entire cell cycle activity, being switched off during the $G_{0}$ phase. $^{1}$ MIB-1 is a related monoclonal antibody that works in paraffin-embedded tissue and recognizes a fixation-resistant epitope of this antigen. ${ }^{2,19,20}$ Neither the exact epitope sequence recognized by the different Ki67 antibodies is known nor the commercial data sheets of the reagents provide any additional information. Despite this lack of information, the various reagents are routinely used as if they were identical, although differences in LI may be obtained using different reagents. $^{21,22}$

The Ki67 cell membrane staining has been sometimes interpreted in the literature as an artifact. However, the possibility of a real cross-reaction by a similar epitope should rather be considered, on the basis of the intense and sometimes crisp membrane staining, which is different from nonspecific background signal.

In this study, we show that only the MIB-1 clone was able to stain the cell membrane in HTT of the thyroid and in the other tumors here collected (cases of breast carcinoma, renal oncocytoma, and mesothelioma). By contrast, we were not able to reproduce the same "artifact" described by Hattori ${ }^{16}$ in $\mathrm{SH}$, where, at least in our cases, only an MIB-1 nuclear pattern was observed, despite the same strong antigen retrieval conditions described by the author ${ }^{16}$ were applied. The other Ki67 antibodies were invariably negative at the cell membrane level (although positive in the proliferating nuclei, as expected). This indicates that the different anti-Ki67 clones either identify different Ki67 epitopes or have a different grade of avidity. This latter possibility is unlikely because MIB-1 clones did not produce membrane staining when the temperature of the immunohistochemical reaction was increased at $37^{\circ} \mathrm{C}$, although it is well known that temperature increases the level of antibody avidity. ${ }^{23}$ Rather, the presence of a partial antigen homology, which may be possibly related to a peculiar neoplastic phenotype, is probably a better explanation, supported by the fact that MIB-1 stained tumor cell membranes are restricted to different types of neoplastic lesions, including HTT cases and, occasionally, sarcomatous mesothelioma, invasive breast carcinoma, and renal oncocytoma. On the other hand, we think that fixation and other tissue processing did not contribute to produce this phenomenon, because similar immunostaining patterns have been observed in cases that have been processed in 3 different laboratories, with similar but not identical protocols of fixation and embedding.

A final issue deserves a comment: when the MIB-1 incubation was performed at $37^{\circ} \mathrm{C}$, such as in the Ventana automated immunostainer, no staining was observed at the cell membrane level, but only in proliferating nuclei, as expected. This apparently paradoxical phenomenon may be explained by a temperature-induced modification of the antigen spatial conformation, that is, tertiary or quaternary molecular arrangement. Despite the increased avidity and affinity of the antibody binding induced by higher temperature, the minimal conformational change of the antigen may prevent the antibody recognition of a partially similar antigen. 
TABLE 1. Type of Ki67 Antibody and Technical Procedures Employed

\begin{tabular}{|c|c|c|c|c|c|c|}
\hline $\begin{array}{l}\text { Primary Ki67 } \\
\text { Clone } \\
\end{array}$ & Source /Dilution & $\begin{array}{c}\begin{array}{c}\text { Detection System } \\
\text { (DakoCytomation) }\end{array} \\
\end{array}$ & $\begin{array}{c}\text { Immunostaining } \\
\text { Procedure }\end{array}$ & $\begin{array}{c}\text { Temperature } \\
\text { Incubation }\end{array}$ & $\begin{array}{l}\text { Nuclear } \\
\text { Staining } \\
\end{array}$ & $\begin{array}{c}\text { Membrane } \\
\text { Staining }\end{array}$ \\
\hline \multirow[t]{6}{*}{ MIB-1 } & $\begin{array}{c}\text { DakoCytomation, } \\
\text { Glostrup, Denmark } \\
1 / 300\end{array}$ & LSAB & Manual & Room & Yes & Yes \\
\hline & & & Automated Dako & Room & Yes & Yes \\
\hline & & & Automated Ventana & $37^{\circ} \mathrm{C}$ & Yes & No \\
\hline & & En Vision & Manual & Room & Yes & Yes \\
\hline & & & Automated Dako & Room & Yes & Yes \\
\hline & & & Automated Ventana & $37^{\circ} \mathrm{C}$ & Yes & NO \\
\hline \multirow[t]{6}{*}{ MIB-1 } & $\begin{array}{l}\text { Immunotech, } \\
\text { Marseilles France }\end{array}$ & LSAB & Manual & Room & Yes & Yes \\
\hline & & & Automated Dako & Room & Yes & Yes \\
\hline & & & Automated Ventana & $37^{\circ} \mathrm{C}$ & Yes & NO \\
\hline & & En Vision & Manual & Room & Yes & Yes \\
\hline & & & Automated Dako & Room & Yes & Yes \\
\hline & & & Automated Ventana & $37^{\circ} \mathrm{C}$ & Yes & NO \\
\hline \multirow[t]{6}{*}{ 7B11 } & $\begin{array}{c}\text { Zymed, San } \\
\text { Francisco, } 1 / 200\end{array}$ & LSAB & Manual & Room & Yes & NO \\
\hline & & & Automated Dako & Room & Yes & NO \\
\hline & & & Automated Ventana & $37^{\circ} \mathrm{C}$ & Yes & NO \\
\hline & & En Vision & Manual & Room & Yes & NO \\
\hline & & & Automated Dako & Room & Yes & NO \\
\hline & & & Automated Ventana & $37^{\circ} \mathrm{C}$ & Yes & NO \\
\hline \multirow[t]{6}{*}{ KIS5 } & $\begin{array}{c}\text { DakoCytomation } \\
1 / 300\end{array}$ & LSAB & Manual & Room & Yes & NO \\
\hline & & & Automated Dako & Room & Yes & NO \\
\hline & & & Automated Ventana & $37^{\circ} \mathrm{C}$ & Yes & NO \\
\hline & & En Vision & Manual & Room & Yes & NO \\
\hline & & & Automated Dako & Room & Yes & NO \\
\hline & & & Automated Ventana & $37^{\circ} \mathrm{C}$ & Yes & NO \\
\hline \multirow[t]{6}{*}{ KI88 } & $\begin{array}{c}\text { Biogenex, San } \\
\text { Ramon (kit dilution) }\end{array}$ & LSAB & Manual & Room & Yes & NO \\
\hline & & & Automated Dako & Room & Yes & NO \\
\hline & & & Automated Ventana & $37^{\circ} \mathrm{C}$ & Yes & NO \\
\hline & & En Vision & Manual & Room & Yes & NO \\
\hline & & & Automated Dako & Room & Yes & NO \\
\hline & & & Automated Ventana & $37^{\circ} \mathrm{C}$ & Yes & $\mathrm{NO}$ \\
\hline \multirow[t]{6}{*}{ SP6 (rabbit) } & $\begin{array}{l}\text { Lab Vision, } \\
\text { Fremont, } 1 / 400\end{array}$ & LSAB & Manual & Room & Yes & NO \\
\hline & & & Automated Dako & Room & Yes & NO \\
\hline & & & Automated Ventana & $37^{\circ} \mathrm{C}$ & Yes & NO \\
\hline & & En Vision & Manual & Room & Yes & NO \\
\hline & & & Automated Dako & Room & Yes & NO \\
\hline & & & Automated Ventana & $37^{\circ} \mathrm{C}$ & Yes & NO \\
\hline
\end{tabular}

FIGURE 1. MIB-1 cell membrane reactivity in hyalinizing trabecular tumor of the thyroid $(A)(250 \times)$, invasive breast carcinoma $(B)(250 \times)$, and renal oncocytoma $(C)(400 \times)$ using an immunoperoxidase procedure at room temperature and a biotin-free detection system. The same cases were negative at the membrane level when MIB-1 was employed in the thyroid tumor at $37^{\circ} \mathrm{C}$ in an automated stainer (D) $(400 \times)$, when the SP6 rabbit monoclonal antibody to $\mathrm{Ki} 67$ was employed in the breast carcinoma $(\mathrm{E})(250 \times)$, and when the 7B11 clone was used in the renal oncocytoma $(F)(400 \times)$.

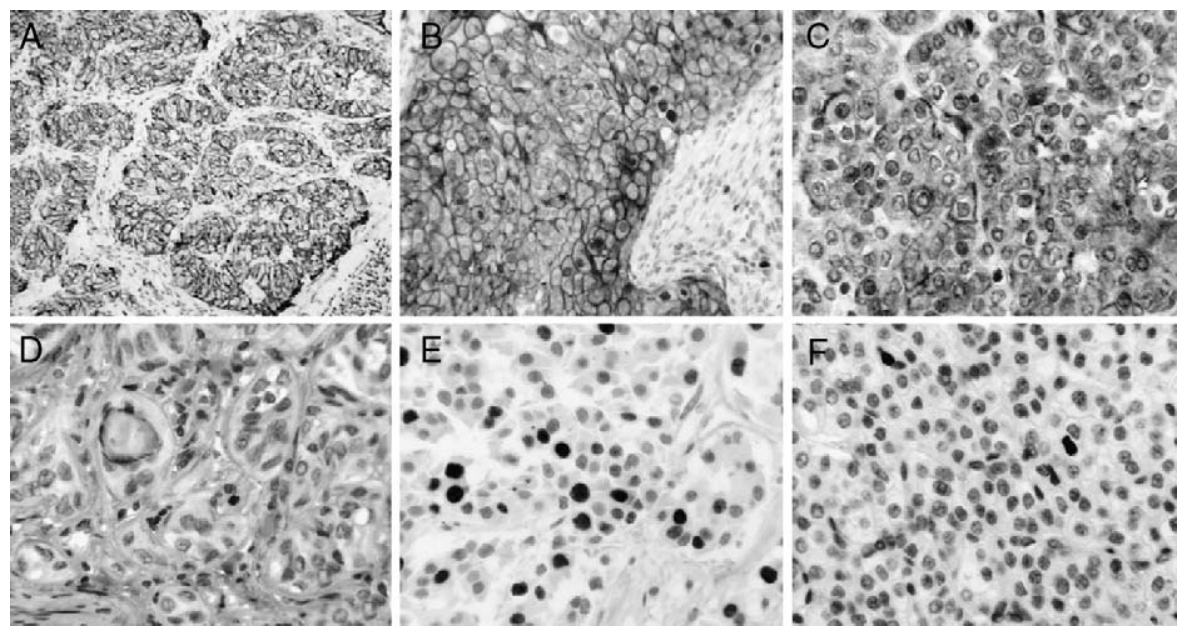


In conclusion, we have shown that the reported Ki67 cell membrane reactivity in some human tumors occurs only when using the MIB-1 monoclonal antibody at room temperature. Therefore, from a practical standpoint, when Ki67 immunohistochemistry is used for diagnostic purposes in the suspicion of HTT, only MIB-1 clone at room temperature should be employed. Conversely, apart from HTT, the role of MIB-1 clone as a diagnostic test should be discouraged until its better definition.

\section{REFERENCES}

1. Gerdes J, Lemke H, Baisch $\mathrm{H}$, et al. Cell cycle analysis of a cell proliferation-associated human nuclear antigen defined by the monoclonal antibody Ki-67. J Immunol. 1984;133:1710-1715.

2. Gerdes J, Li L, Schlueter C, et al. Immunobiochemical and molecular biologic characterization of the cell proliferation-associated nuclear antigen that is defined by monoclonal antibody $\mathrm{Ki}-67$. Am J Pathol. 1991;138:867-873.

3. Oosterhuis JW, Schapers RF, Janssen-Heijnen ML, et al. MIB-1 as a proliferative marker in transitional cell carcinoma of the bladder: clinical significance and comparison with other prognostic factors. Cancer. 2000;88:2598-2605.

4. Schipper DL, Wagenmans MJ, Peters WH, et al. Significance of cell proliferation measurement in gastric cancer. Eur J Cancer. 1998;34: 781-790.

5. Gentil Perret A, Mosnier JF, Buono JP, et al. The relationship between MIB-1 proliferation index and outcome in pancreatic neuroendocrine tumors. Am J Clin Pathol. 1998;109:286-293.

6. Szadowska A, Olborski B, Harezga-Bal B, et al. Expression of P53, MDM2 and Ki-67 antigens in soft tissue sarcomas. Pol J Pathol. 1999;50:9-16.

7. Zoya K, Arbiser MD, Jack L, et al. Neuroendocrine lung tumors: grade correlates with proliferation but not angiogenesis. Mod Pathol. 2001;14:1195-1199.

8. DeLellis RA, Lloyd RV, Heitz PhU, et al. WHO Classification of tumors. Pathology and Genetics: Tumors of Endocrine Organs. Lyon: IARC Press; 2004:126, 141.

9. Davaris P, Helpap B, Kollermann J. Assessment of basal cell status and proliferative patterns in flat and papillary urothelial lesions: a contribution to the new WHO classification of the urothelial tumors of the urinary bladder. Hum Pathol. 2000;31:745-750.
10. Mittal K. Utility of proliferation-associated marker MIB-1 in evaluating lesions of the uterine cervix. Adv Anat Pathol. 1999;6: $177-185$.

11. Cibull ML, Heryet A, Gatter KC, et al. Y. The utility of Ki-67 immunostaining, nuclear organizer region counting, and morphology in the assessment of follicular lymphomas. J Pathol. 1989;158: $189-193$.

12. Casey MB, Sebo TJ, Carney JA. Hyalinizing trabecular adenoma of the thyroid gland identification through MIB-1 staining of fineneedle aspiration biopsy smears. Am J Clin Pathol. 2004;122: 506-510.

13. Hirokawa M, Shimizu M, Manabe T, et al. Hyalinizing trabecular adenoma of the thyroid: its unusual cytoplasmic immunopositivity for MIB1. Pathol Int. 1995;45:399-401.

14. Boerner SL, Asa SL. Hyalinizing trabecular tumor of the thyroid gland: much ado about nothing? Am J Clin Pathol. 2004;122: 495-496.

15. Papotti M, Riella $\mathrm{P}$, Montemurro $\mathrm{F}$, et al. Immunophenotypic heterogeneity of hyalinizing trabecular tumours of the thyroid. Histopathology. 1997;31:525-533.

16. Hattori $\mathrm{H}$. Sclerosing hemangioma of the lung is positive for MIB-1 in cell membrane and cytoplasmic staining pattern. Histopatology. 2002;40:291-293.

17. Papotti M, Volante M, Giugliano A, et al. RET expression in hyalinizing trabecular tumor of the thyroid gland. Am J Surg Pathol. 2000;24:1615-1621.

18. Rossi S, Laurini L, Furlanetto A, et al. Rabbit monoclonal antibodies. A comparative study between a novel category of immunoreagents and the corresponding mouse monoclonal antibodies. Am J Clin Pathol. 2005;124:295-302.

19. Key G, Becker MH, Baron B, et al. New Ki-67-equivalent murine monoclonal antibodies (MIB 1-3) generated against bacterially expressed parts of the Ki-67 cDNA containing three 62 base pair repetitive elements encoding for the Ki-67 epitope. Lab Invest. 1993;68:629-636.

20. Scholzen T, Gerdes J. The Ki-67 protein: from the known and the unknown. J Cell Physiol. 2000;182:311-322.

21. Barbareschi M, Girlando S, Mauri FM, et al. Quantitative growth fraction evaluation with MIB1 and Ki67 antibodies in breast carcinomas. Am J Clin Pathol. 1994;102:171-175.

22. Mauri Fa, Girlando S, Dalla Palma P, et al. Ki67 antibodies (Ki-S5, MIB1, Ki67) in breast carcinomas. A brief quantitative comparison. Appl Immunohistochem. 1994;2:171-176.

23. Absolom DR: The nature of the antigen-antibody bond and the factors affecting its association and dislocation. Crit Rev Immunol. 1986;6:1-46. 